\title{
Synthesis of Cobalt Nanowires on Porous Anodic Alumina Template Using Electrochemical Deposition
}

\author{
C.K. Chung ${ }^{*}$, S.H. Wu, C.R. Hsu, C.H. Tsai and I.C. Chung
}

Department of Mechanical Engineering, and Center for Micro/Nano Science and Technology, National Cheng Kung University, Tainan 701, Taiwan

\begin{abstract}
Electrochemical deposition has been widely used for synthesis of metal nanowires (NWs) on the porous template. In this paper, the effect of potential and electrolyte concentration on cobalt (Co) NWs formation through porous anodic alumina template has been investigated using direct-current electrodepostion at $0.75 \sim 2 \mathrm{~V}$ together with the high $0.5 \mathrm{M}$ and low $0.1 \mathrm{M}$ cobalt sulfurate based electrolyte. Scanning electron microscopy and grazing incidence X-ray diffraction were used to examine the nanostructure, morphology and phase of Co NWs. The current vs time curve was recorded for understanding the growth behavior. Too low potential of $0.75 \mathrm{~V}$ is not favored for Co NWs formation due to insufficient driving force while too high potential of $2 \mathrm{~V}$ ruins the NWs growth owing to hydrogen generation in reduction reaction. The uniform crystalline Co NWs can be obtained by the proper potential of $1 \mathrm{~V}$ and concentration of $0.5 \mathrm{M}$ at an average growth rate of $964 \mathrm{~nm} / \mathrm{min}$.
\end{abstract}

Received on 19-11-2015 Accepted on 16-12-2015 Published on 05-01-2016

Keywords: Anodic alumina, electrochemical deposition, cobalt nanowires, porous template.

\section{INTRODUCTION}

Nanostructured materials are of great interest in theoretical physics, solid state science and technological applications. Among the nanoscale materials, the one-dimensional nanomaterials, especially one-dimensional magnetic metal or metal oxide materials, have attracted much attention because of their specific magnetic [1-3], capacitance [4], optical [5] and biocompatible [6] properties for fundamental research and potential applications. The ferromagnetic nanowire arrays in many works were focused on the magnetization behavior and high-density magnetic recording media. Methods used to produce metallic nanowires (NWs) can be categorized as both the lithography-etching patterning method [7] and the 'template synthesis' one [8-10]. The former is comparatively complex, expensive and not suitable for large scale production while the latter involves electrochemically depositing metal into nanopores of the template. Generally, the template method is cheap and easy to operate, and has diameters ranging from several nanometres to hundreds of nanometres in a large area under proper control for nanowires synthesis. The anodic aluminium oxide (AAO) template [11-15] has been widely studied for various categories due to its remarkable properties such as

"Department of Mechanical Engineering, and Center for Micro/Nano Science and Technology, National Cheng Kung University, Tainan 701, Taiwan; Tel: 886-6-2757575 ext. 62111; Fax: 886-6-2352973;

E-mail: ckchung@mail.ncku.edu.tw corrosion resistance, decorative properties, and nanopore regularity [16-19]. The arrangement and structure of nanowires are of importance in the electronic, optical and magnetic properties. The crystalline or amorphous structure is essentially different and compared from the experimental results and theoretical study. The process parameters employed in the deposition such as electrolyte concentration, deposition voltage and temperature are responsible for the structure and properties of nanowire arrays [20-22]. For onedimensional magnetic metal or metal oxide materials, the properties of the nanowires array is related to the character of individual nanowire and the periodicity or the symmetry of nanowires. The properties concerned with the crystallization and symmetry of nanowire arrays was studied by the AAO template method at fixed diameter [23]. For example, cobalt (Co) in hcp crystallographic form had the c axis as the easy axis of magnetization. When the $c$ axis was perpendicular to the film plane, the film exhibited a large perpendicular magnetic anisotropy [24-26]. Thus, it is important to study the crystallographic orientation of Co grains in the pores. Many researches has focused on changing the characteristics of the template or varying the electrodeposited parameters [10, $23,27]$. In order to control the length and uniformity of the Co NWs, the voltage and concentration are of great importance during electrochemical deposition. In this paper, the effect of potential and electrolyte concentration on Co NWs formation through porous AAO template has been investigated using direct-current electrodepostion at $0.75 \sim 2 \mathrm{~V}$ together with the 
high $0.5 \mathrm{M}$ and low $0.1 \mathrm{M}$ cobalt sulfurate based electrolyte. The current vs time curve is recorded for understanding the growth behavior. The crystallized and more-uniform Co NWs can be obtained by the proper potential and concentration.

\section{EXPERIMENTAL PROCEDURES}

The commercial anodic aluminum oxide (Whatman Anodisc, England) template with the nominal avearge pore diameter of about $200 \mathrm{~nm}$ and thickness of $60 \mu \mathrm{m}$ was used for electrochemical deposition of Co NWs. Figure 1 showed the schematic process flow of the electrochemical deposition of Co NWs into the through-hole AAO template. First, the commercial AAO template was pre-evaporated with the titanium and aluminum (Ti-Al) conductive layer. The Ti metal is benificial for enhancing the adhesion of Al onto AAO. The opposite side of through pores remained open for deposition via metal ions diffusion and migration. Then the Ti-Al coated AAO template was cut into pieces of $0.9 \mathrm{~cm} \times 0.9 \mathrm{~cm}$ in size which was mounted onto a copper foil for easy experimental handling. Various concentrations of electrolytes were prepared in volume of $300 \mathrm{ml}$ for each deposition with low 0.1 $\mathrm{M}$ and high $0.5 \mathrm{M} \mathrm{CoSO}_{4} \cdot 7 \mathrm{H}_{2} \mathrm{O}$, respectively, mixed with $0.5 \mathrm{M}$ boric acid. Before electrochemical deposition, the sample was immersed into the deionized water for ultrasonic cleaning for $10 \mathrm{~min}$. The electrochemical deposition was performed by means of potentiostat (Jiehan 5000, Taiwan) and the three-electrode electrochemical cell that consisted of the copper foil as working electrode, the copper foil as

(a)

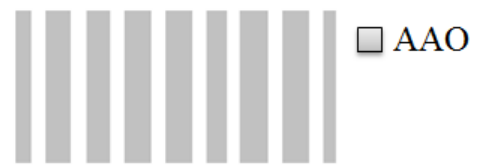

(b)

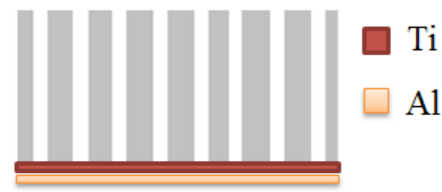

(c)

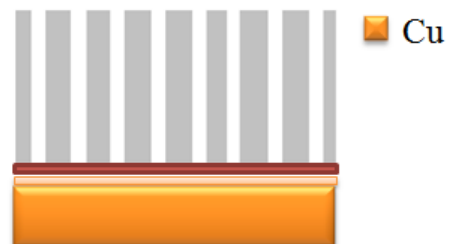

(d)

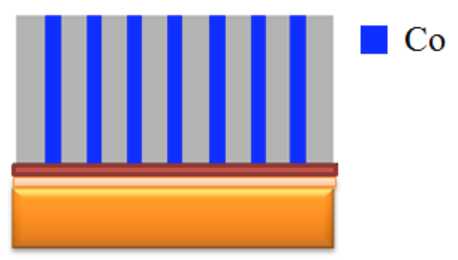

Figure 1: Schematic process flow of the electrochemical deposition of Co nanowires into the through-hole AAO template: (a) a commercial AAO template, (b) sputtering a Ti/Al conductive seed layer, (c) the Cu substrate as the bottom for easy handling and (d) adjusting parameters to electrodeposit Co nanowires. counter electrode, and the standard calomel electrode as reference electrode. The depotention potential was operated by direct-current (DC) mode at $0.75 \sim 2 \mathrm{~V}$ at $25{ }^{\circ} \mathrm{C}$ for 10 minutes. All deposition conditions of various voltage and concentration are listed in Table $\mathbf{1}$ for comparison. The current vs time curve was recorded during electrochemical deposition. The characteristics of Co NWs was examined by high resolution thermal field emission scanning electron microscopy (JEOL JSM-7000F, Japan). The crystal structure of Co NWs was investigated by grazing incidence X-ray diffractometer (XRD, D8 Discover, Germany). The diffraction spectra were obtained in the $2 \theta$ range from $20 \sim 80^{\circ}$ at a scan rate of 0.05 degree per second.

Table 1: The Relationship of the Electrolyte Concentration, Deposition Voltage and Length of Co Nanowires Using DC Electrode Position

\begin{tabular}{|c|c|c|}
\hline Electrolyte & Voltage & Length \\
\hline \hline $0.5 \mathrm{MCoSO}_{4} \cdot 7 \mathrm{H}_{2} \mathrm{O}+0.5 \mathrm{M} \mathrm{H}_{3} \mathrm{BO}_{3}$ & $-0.75 \mathrm{~V}$ & Fail \\
\hline $0.5 \mathrm{MCoSO}_{4} \cdot 7 \mathrm{H}_{2} \mathrm{O}+0.5 \mathrm{M} \mathrm{H}_{3} \mathrm{BO}_{3}$ & $-1 \mathrm{~V}$ & $9.64 \pm 1.1 \mu \mathrm{m}$ \\
\hline $0.5 \mathrm{MCoSO}_{4} \cdot 7 \mathrm{H}_{2} \mathrm{O}+0.5 \mathrm{M} \mathrm{H}_{3} \mathrm{BO}_{3}$ & $-1.5 \mathrm{~V}$ & $34.30 \pm 6.4 \mu \mathrm{m}$ \\
\hline $0.5 \mathrm{MCoSO}_{4} \cdot 7 \mathrm{H}_{2} \mathrm{O}+0.5 \mathrm{M} \mathrm{H}_{3} \mathrm{BO}_{3}$ & $-2 \mathrm{~V}$ & $35.09 \pm 8.3 \mu \mathrm{m}$ \\
\hline $0.1 \mathrm{MCoSO}_{4} \cdot 7 \mathrm{H}_{2} \mathrm{O}+0.5 \mathrm{M} \mathrm{H}_{3} \mathrm{BO}_{3}$ & $-1 \mathrm{~V}$ & $8.83 \pm 2.3 \mu \mathrm{m}$ \\
\hline $0.5 \mathrm{MCoSO}_{4} \cdot 7 \mathrm{H}_{2} \mathrm{O}+0.5 \mathrm{M} \mathrm{H}_{3} \mathrm{BO}_{3}$ & $-1 \mathrm{~V}$ & $9.64 \pm 1.1 \mu \mathrm{m}$ \\
\hline $0.1 \mathrm{MCoSO}_{4} \cdot 7 \mathrm{H}_{2} \mathrm{O}+0.5 \mathrm{M} \mathrm{H}_{3} \mathrm{BO}_{3}$ & $-1.5 \mathrm{~V}$ & $15.56 \pm 3.2 \mu \mathrm{m}$ \\
\hline $0.5 \mathrm{MCoSO}_{4} \cdot 7 \mathrm{H}_{2} \mathrm{O}+0.5 \mathrm{M} \mathrm{H}_{3} \mathrm{BO}_{3}$ & $-1.5 \mathrm{~V}$ & $34.30 \pm 6.4 \mu \mathrm{m}$ \\
\hline
\end{tabular}

\section{RESULTS AND DISCUSSION}

Figure 2 shows the relationship between the current density and deposition time of Co NWs through commercial AAO of $200 \mathrm{~nm}$ in pore diameter at DC potentials of $0.75 \mathrm{~V}, 1 \mathrm{~V}, 1.5$ $\mathrm{V}$ and $2 \mathrm{~V}$. The current density increases with increasing potential except for $0.75 \mathrm{~V}$ of which current density tends to zero. It is because the $0.75 \mathrm{~V}$ is lower than cobalt NWs reaction potential. Also, the current density at high $2 \mathrm{~V}$ with a rapid increase at the initial stage is attributed to unstable growth behavior. The formation of Co nanowires can be examined by the SEM cross section as shown in Figure 3. No Co nanowires is found at low $0.75 \vee$ (Figure 3a) while the length of nanowires increases with DC potential at 1 2 V (Figure $3 b-d$ ). It is consistent with the current density evolution. Higher current density corresponds to high reaction rate for longer wires and no current is for no wire. The reaction potential of Co NWs through $200 \mathrm{~nm}$ AAO is between $0.75 \mathrm{~V}$ and $1 \mathrm{~V}$. When $1 \mathrm{~V}$ potential is applied, the cobalt ions diffuse and migrate into pores to gather for nucleation and growth of nanowires. So the initial current density increases substantially and then becomes steady with increasing deposition time. The grown nanowires are uniform as shown in Figure $\mathbf{3 b}$. As the potential increases to $1.5 \mathrm{~V}$, the current density initially increases in a manner similar to that at $1 \mathrm{~V}$ but it continues to significantly increase with time. The non-steady state growth leads to the non-uniform longer nanowires formation as shown in Figure 3c. The non-uniform 


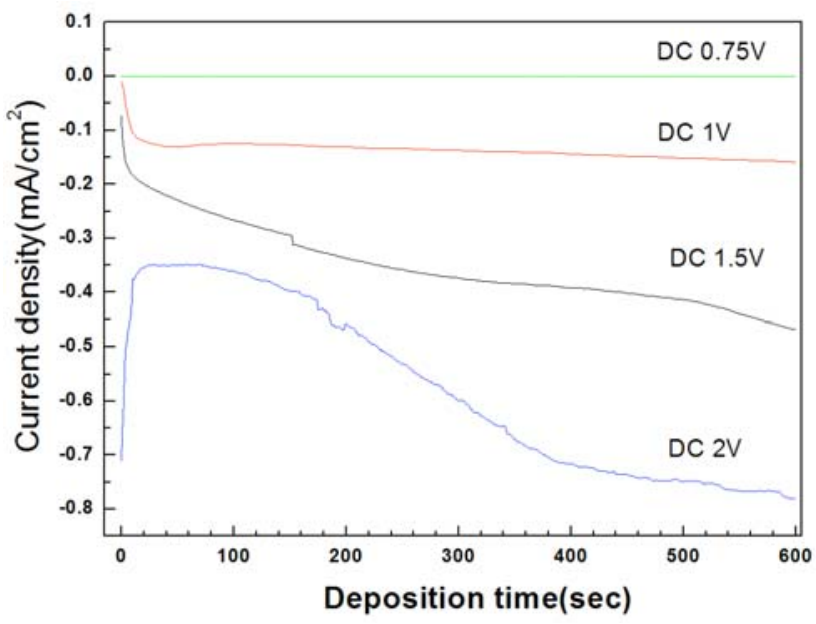

Figure 2: Current density vs. time curves of Co nanowires formation at different $\mathrm{DC}$ voltages of $0.75 \mathrm{~V}, 1 \mathrm{~V}, 1.5 \mathrm{~V}$ and $2 \mathrm{~V}$ in the same electrolyte of $0.5 \mathrm{M} \mathrm{CoSO}_{4} \cdot 7 \mathrm{H}_{2} \mathrm{O}+0.5 \mathrm{M} \mathrm{H}_{3} \mathrm{BO}_{3}$.

growth is concerned with the hydrogen gas formation during reduction. Without stirring during electrodepositon, the charge transfer speed attributed to potential is higher than cobalt ions diffusion rate which is caused by concentration gradient from reduction reaction. Therefore, the hydrogen ions which migrate faster than cobalt ions can easily result in large amount of hydrogen for poor uniformity. It becomes more severe at the condition of $2 \mathrm{~V}$. The longer and highly nonuniform nanowires is found and even the Co clusters is formed on the surface of AAO as shown in Figure $\mathbf{3 d}$. The cluster growth on surface may be linked to the mentioned unstable growth behavior with initial abrupt increase of current at $2 \mathrm{~V}$ in Figure 2 which is different from the others. The strong charge transfer caused by the highest $2 \mathrm{~V}$ voltage leads to a great number of cobalt ions consumed in the pores of AAO substrate and accelerates Co ions reduction for the formation of non-uniform length of NWs and Co clusters on the surface of $A A O$. The mean lengths with deviation of $C_{0}$ NWs at $1 \mathrm{~V}, 1.5 \mathrm{~V}$ and $2 \mathrm{~V}$ are $9.64 \pm 1.1 \mu \mathrm{m}, 34.30 \pm 6.4 \mu \mathrm{m}$ and $35.09 \pm 8.3 \mu \mathrm{m}$, respectively, as listed in Table 1. The growth rate increases with voltage and the best uniformity of NWs occurs at $1 \mathrm{~V}$.

Besides the voltage, the electrolyte concentration can also affect the current density and nanowire growth. Because 0.75 $\mathrm{V}$ is too low to grow and $2.0 \mathrm{~V}$ is too high for closter, we use the proper $1 \mathrm{~V}$ and $1.5 \mathrm{~V}$ together with the electrolyte concentration of $0.5 \mathrm{M}$ and $0.1 \mathrm{M} \mathrm{CoSO}_{4} \cdot 7 \mathrm{H}_{2} \mathrm{O}$ at constant $0.5 \mathrm{M} \mathrm{H}_{3} \mathrm{BO}_{3}$ for electrodeposition at $25{ }^{\circ} \mathrm{C}$ for comparison as listed in Table 1. Figure 4 shows the current density vs. time curves of Co NWs formation at proper DC voltages of $1 \mathrm{~V}$ and $1.5 \mathrm{~V}$ in the low $0.1 \mathrm{M}$ and high $0.5 \mathrm{M} \mathrm{CoSO}_{4} \cdot 7 \mathrm{H}_{2} \mathrm{O}$. The current density decrease with electrolyte concentration at

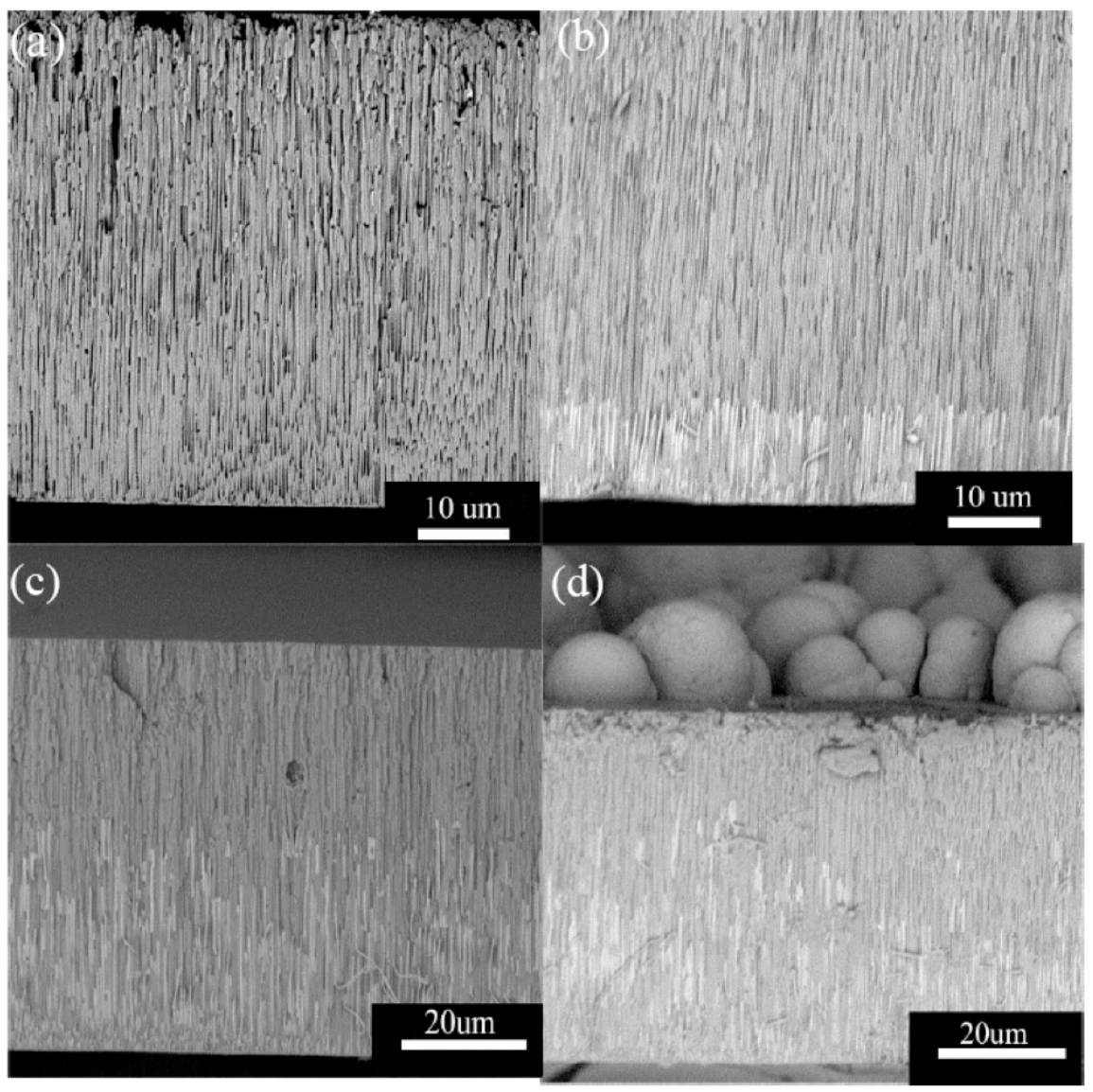

Figure 3: SEM micrographs of Co nanowires formation at different $\mathrm{DC}$ voltages of: (a) $0.75 \mathrm{~V}$, (b) $1 \mathrm{~V},(\mathbf{c}) 1.5 \mathrm{~V}$ and (d) $2 \mathrm{~V}$ in the same electrolyte of $0.5 \mathrm{M} \mathrm{CoSO}_{4} \cdot 7 \mathrm{H}_{2} \mathrm{O}+0.5 \mathrm{M} \mathrm{H}_{3} \mathrm{BO}_{3}$. 


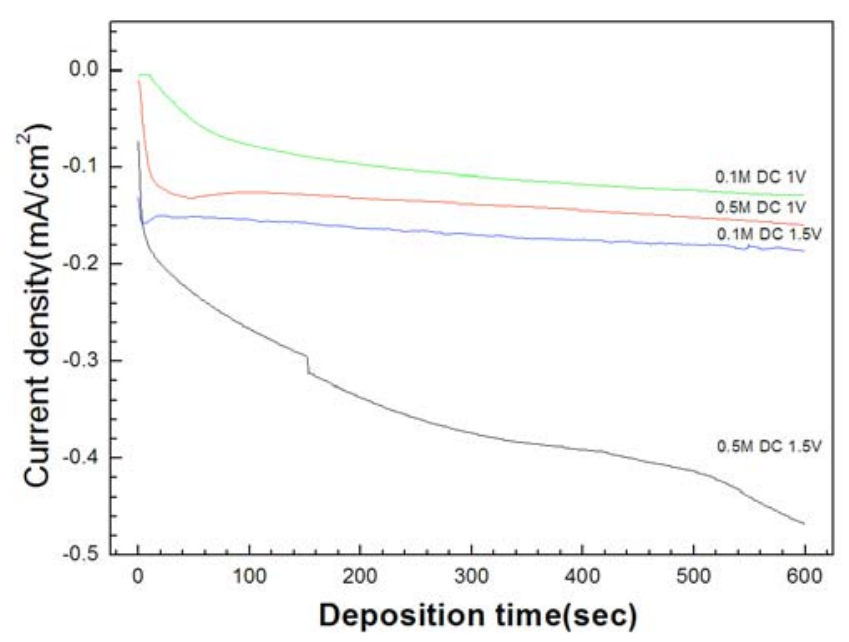

Figure 4: Current density vs. time curves of Co nanowires formation at proper $\mathrm{DC}$ voltages of $1 \mathrm{~V}$ and $1.5 \mathrm{~V}$ in the low $0.1 \mathrm{M}$ and high 0.5 $\mathrm{M} \mathrm{CoSO}_{4} \cdot 7 \mathrm{H}_{2} \mathrm{O}$ together with $0.5 \mathrm{M} \mathrm{H}_{3} \mathrm{BO}_{3}$.

constant voltage and it is higher for the sampling on the condition of $(0.1 \mathrm{M}, 1.5 \mathrm{~V})$ than that at $(0.5 \mathrm{M}, 1 \mathrm{~V})$. Three samples performed at the conditions of $(0.1 \mathrm{M}, 1 \mathrm{~V}),(0.5 \mathrm{M}, 1$ $\mathrm{V})$ and $(0.1 \mathrm{M}, 1.5 \mathrm{~V})$ exhibit the steady cuurent at the prolonged time while the $(0.5 \mathrm{M},-1.5 \mathrm{~V})$ sample has the nonsteady current behavior. The growth behavior of Co NWs in the above four samples is examined by SEM cross section as shown in Figure 5. The corresponding lengths of the nanowires at the conditions of $(0.1 \mathrm{M}, 1 \mathrm{~V}),(0.5 \mathrm{M}, 1 \mathrm{~V}),(0.1$ $\mathrm{M}, 1.5 \mathrm{~V})$ and $(0.5 \mathrm{M}, 1.5 \mathrm{~V})$ are $8.83 \pm 2.3 \mu \mathrm{m}, 9.64 \pm 1.1 \mu \mathrm{m}$, $15.56 \pm 3.2 \mu \mathrm{m}$ and $34.30 \pm 6.4 \mu \mathrm{m}$, respectively, as listed in Table 1. The mean length of Co NWs increases with the current density and the sample at the condition of $(0.5 \mathrm{M}, 1$ $\mathrm{V})$ has the best uniformity. It indicates low concentration is not good for the formation of uniform nanowires and the optimum condition in this study is at $(0.5 \mathrm{M}, 1 \mathrm{~V})$. The effect of voltage gradient induced ions migration is more important for uniform nanowires growth than concentration gradient induced diffusion.

The deposition voltage and electrolyte concentration also affect the crystallinity of Co NWs. Figure 6 shows the GIXRD patterns of four samples of Co NWs deposited at the parameter conditions of $(0.5 \mathrm{M}, 1 \mathrm{~V}),(0.5 \mathrm{M}, 1.5 \mathrm{~V}),(0.1 \mathrm{M}, 1$ $\mathrm{V})$ and $(0.1 \mathrm{M}, 1.5 \mathrm{~V})$, respectively. The main diffraction peaks are from the crystalline $\mathrm{Al}$ seed layer and Co NWs. Four Co diffraction planes are identified as (100), (002), (101)
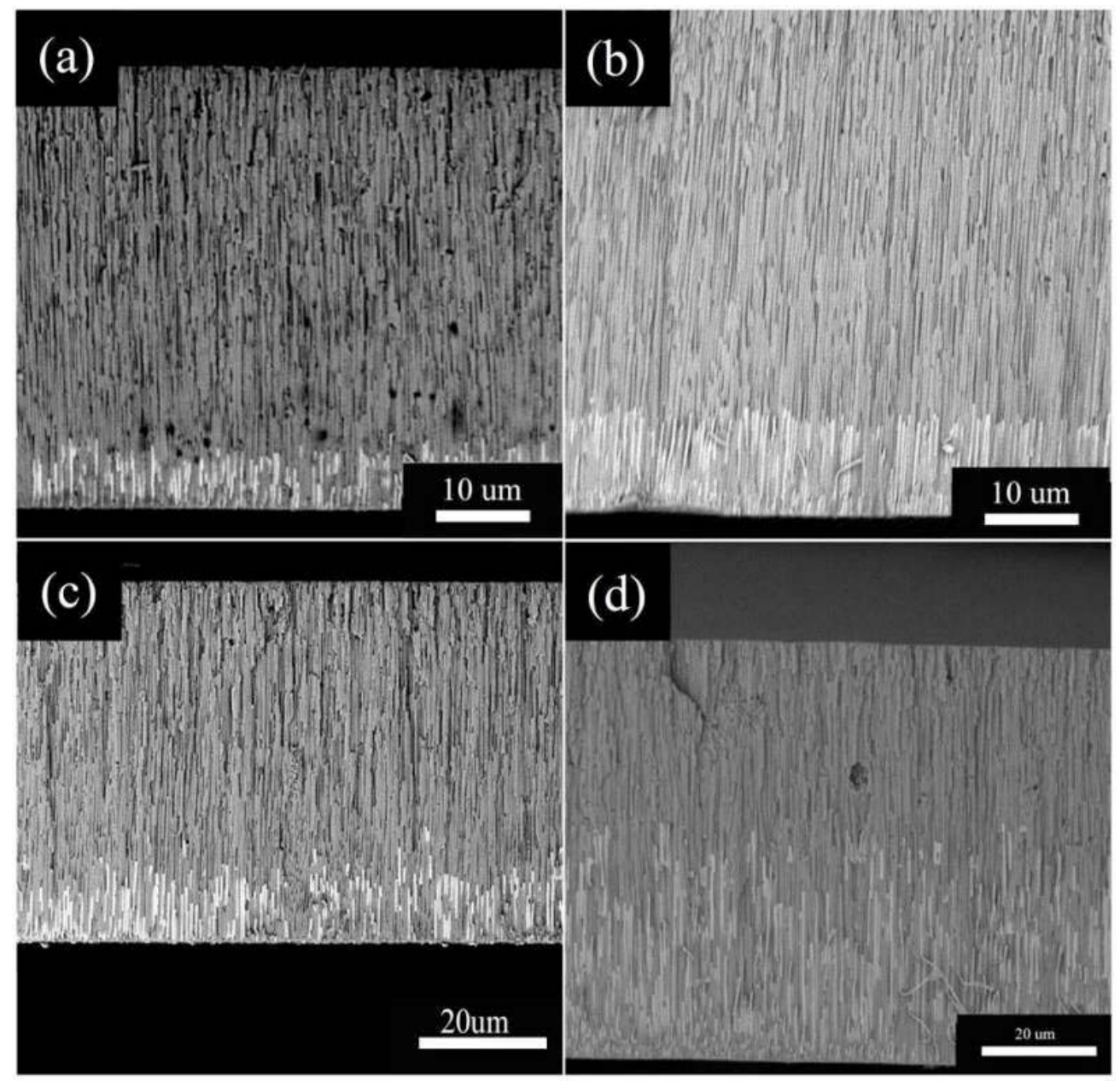

Figure 5: SEM micrographs of Co nanowires formation at different parameters of (DC voltages, concentration) of: (a) $(0.1 \mathrm{M}, 1 \mathrm{~V}),(\mathbf{b})(0.5 \mathrm{M}, 1 \mathrm{~V})$, (c) $(0.1 \mathrm{M}, 1.5 \mathrm{~V})$, and $(\mathrm{d})(0.5 \mathrm{M}, 1.5 \mathrm{~V})$. 
and (110). It indicates the electrodeposited Co NWs are polycrystalline. It is noted that both the $(0.5 \mathrm{M}, 1 \mathrm{~V})$ and $(0.5$ $\mathrm{M}, 1.5 \mathrm{~V}$ ) samples have greatly higher intensity of crystalline Co than the other $(0.1 \mathrm{M}, 1 \mathrm{~V})$ and $(0.1 \mathrm{M}, 1.5 \mathrm{~V})$ ones. It reveals that the electrolyte concentration is an important factor for degree of crystallinity because the high enough concentration with larger gradient of driving force for diffusion can speed crystallization of Co NWs. Also, the samples deposited at $1 \mathrm{~V}$ has higher intensity than that at $1.5 \mathrm{~V}$ i.e. the $(0.5 \mathrm{M}, 1 \mathrm{~V})$ higher than $(0.5 \mathrm{M}, 1.5 \mathrm{~V})$ and the $(0.1 \mathrm{M}, 1 \mathrm{~V})$ higher than $(0.1 \mathrm{M}, 1.5 \mathrm{~V})$. It implies that the better uniformity at $1 \mathrm{~V}$ benefits for the crystallization of Co NWs. The optimum condition at $(0.5 \mathrm{M}, 1 \mathrm{~V})$ with the best uniform NWs has a preferred orentation along. In a brief, the concentration gradient induced diffusion is more related to crystallization of Co NWs while the voltage induced ions migration is more concerned with uniform nanowires growth together with the preferred orentation.

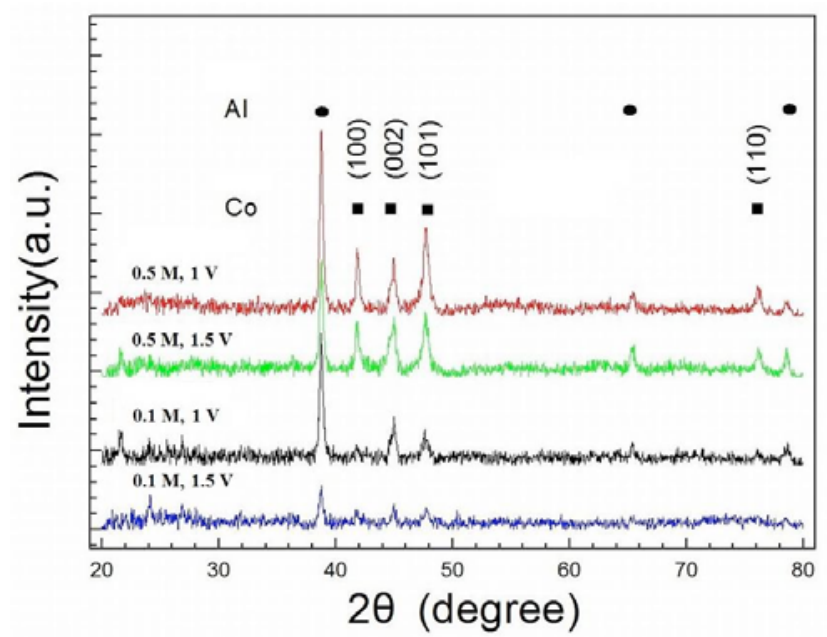

Figure 6: GIXRD patterns of Co nanowires deposited at different parameters of (DC voltages, concentration) of $(0.5 \mathrm{M}, 1 \mathrm{~V}),(0.5 \mathrm{M}, 1.5$ $\mathrm{V}),(0.1 \mathrm{M}, 1 \mathrm{~V})$ and $(0.1 \mathrm{M}, 1.5 \mathrm{~V})$.

\section{CONCLUSION}

The depostion potential and electrolyte concentration affect the characteristics of Co NWs deposited in AAO template. The direct-current electrodepostion at 0.75 2 $\mathrm{V}$ together with the high $0.5 \mathrm{M}$ and low $0.1 \mathrm{M}$ electrolyte concentration have been studied. In terms of potential at $0.5 \mathrm{M}$, the high-voltageinduced high current density corresponds to high reaction rate for longer wires and no current is for no wire. Therfore, too small potential of $0.75 \mathrm{~V}$ will cause no cobalt ions reduction while the increased potential accelerates ion reaction for the prolonged NWs. But too high potential of $2 \mathrm{~V}$ will reduce uniformity of NWs. That is, the effect of voltage gradient induced ions migration is more important for uniform nanowires growth than concentration gradient induced diffusion. In terms of electrolyte concentration, the high concentration of $0.5 \mathrm{M}$ benefits for high degree of crystallinity and better uniformity. In contrast, low concentration of $0.1 \mathrm{M}$ is not good for the formation of uniform NWs together with low crystallinity. The optimum condition is the $0.5 \mathrm{M}$ concentration and $-1 \mathrm{~V}$ potential which can result in the stable nanowire growth and high crystallization of which preferred orentation is along.

\section{ACKNOWLEDGEMENTS}

This work is partial sponsored by National Science Council (NSC) under contract No NSC 99-2221-E-006-032-MY3 and NSC 101-2628-E-006-012-MY3. We pay our great thanks to the Center for Micro/Nano Science and Technology (CMNST) in National Cheng Kung University for the access of process and analysis equipments.

\section{REFERENCES}

[1] Armyanov S. Crystallographic structure and magnetic properties of electrodeposited cobalt and cobalt alloys. Electrochimica Acta 2000; 45: 3323-35.

http://dx.doi.org/10.1016/S0013-4686(00)00408-4

[2] Bran C, Ivanov YP, Trabada DG, et al. Structural dependence of magnetic properties in co-based nanowires: experiments and micromagnetic simulations. IEEE Trans Magnetics 2013: 49: 4491-7. http://dx.doi.org/10.1109/TMAG.2013.2254704

[3] Cortes A, Lavin R, Denardin JC, et al. Template assisted electrochemical growth of cobalt nanowires: influence of deposition conditions on structural, optical and magnetic properties. J Nanosci Nanotech 2011; 11: 3899-910. http://dx.doi.org/10.1166/inn.2011.3826

[4] Asano Y, Komatsu T, Murashiro K, Hoshino K. Capacitance studies of cobalt compound nanowires prepared via electrodeposition. J Power Sources 2011; 196: 5215-22.

http://dx.doi.org/10.1016/j.jpowsour.2011.01.101

[5] Meher SK, Rao GR. Effect of microwave on the nanowire morphology, optical, magnetic, and pseudocapacitance behavior of $\mathrm{Co}_{3} \mathrm{O}_{4}$. J Phys Chem C 2011; 115: 25543-56.

http://dx.doi.org/10.1021/ip209165v

[6] Xuan S, Wang F, Lai JMY, et al. Synthesis of biocompatible, mesoporous $\mathrm{Fe}_{3} \mathrm{O}_{4}$ nano/microspheres with large surface area for magnetic resonance imaging and therapeutic applications. Appl Mater Interfaces 2011; 3: 237-44.

\section{http://dx.doi.org/10.1021/am1012358}

[7] McClelland GM, Hart MW, Rettner CT, Best ME, Carter KR, Terris BD. Nanoscale patterning of magnetic islands by imprint lithography using a flexible mold. Appl Phys Lett 2002; 81: 1483-5.

http://dx.doi.org/10.1063/1.1501763

Cui CX, Wang BL, Yang W, Sun JB. Effect of deposition voltage and $\mathrm{Co}^{2+}$ concentration on the texture and magnetic properties of $\mathrm{Co}$ nanowire arrays. J Cryst Growth 2011; 324: 168-71.

http://dx.doi.org/10.1016/i.jcrysgro.2011.02.016

[9] Ferre R, Ounadjela K, George JM, Piraux L, Dubois S. Magnetization processes in nickel and cobalt electrodeposited nanowires. Phys Rev B 1997; 56: 14066-75.

http://dx.doi.org/10.1103/PhysRevB.56.14066

[10] Kartopu G, Yalcin O, Es-Souni M, Basaran AC. Magnetization behavior of ordered and high density Co nanowire arrays with varying aspect ratio. J Appl Phys 2008; 103: 093915. http://dx.doi.org/10.1063/1.2917191

[11] Masuda H, Fukuda K. Ordered metal nanohole arrays made by a twostep replication of honeycomb structures of anodic alumina. Science 1995; 268: 1466-8.

http://dx.doi.org/10.1126/science.268.5216.1466

[12] Routkevitch D, Tager AA, Haruyama J, Almawlawi D, Moskovits $M$ $\mathrm{Xu}$ JM. Non-lithographic nano-wire arrays: fabrication, physics, and device applications. IEEE Trans. Electron. Dev. 1996; 43: 1646-58. http://dx.doi.org/10.1109/16.536810

[13] Li AP, Muller F, Birner A, Nielsch K, Gosele U. Hexagonal pore arrays with a 50-420 nm interpore distance formed by self-organization in anodic alumina. J Appl Phys 1998; 84: 6023-6. http://dx.doi.org/10.1063/1.368911

[14] Li F, Zhang L, Metzger RM. On the growth of highly ordered pores in anodized aluminum oxide. Chem. Mater. 1998; 10: 2470-80. http://dx.doi.org/10.1021/cm980163a 
[15] Sun Z, Kim HK. Growth of ordered, single-domain, alumina nanopore arrays with holographically patterned aluminum films. Appl Phys Lett 2002; 81: 3458.

http://dx.doi.org/10.1063/1.1517719

[16] Zhai T, Li L, Ma Y, et al. One-dimensional inorganic nanostructures: synthesis, field-emission and photodetection. Chem Soc Rev 2011; 40: 2986-3004 http://dx.doi.org/10.1039/c0cs00126k

[17] Chung CK, Zhou RX, Liu TY, Chang WT. Hybrid pulse anodization for the fabrication of porous anodic alumina films from commercial purity $(99 \%)$ aluminum at room temperature. Nanotechnology 2009; 20 : 055301.

http://dx.doi.org/10.1088/0957-4484/20/5/055301

[18] Minguez-Bacho I, Rodriguez-Lopez S, Vazquez M, Hernandez-Velez $M$, Nielsch K. Electrochemical synthesis and magnetic characterization of periodically modulated Co nanowires. Nanotechnology 2014; 25: 145301

http://dx.doi.org/10.1088/0957-4484/25/14/145301

[19] Chung CK, Chang WT, Liao MW, Chang HC, Lee CT. Fabrication of enhanced anodic aluminum oxide performance at room temperatures using hybrid pulse anodization with effective cooling. Electrochim Acta 2011; 56: 6489-97.

http://dx.doi.org/10.1016/i.electacta.2011.04.122

[20] Proenca MP, Merazzo KJ, Vivas LG, et al. Co nanostructures in ordered templates: comparative FORC analysis. Nanotechnology 2013; 24; 475703

http://dx.doi.org/10.1088/0957-4484/24/47/475703

[21] Qin J, Nogues J, Mikhaylova M, Roig A, Munoz JS, Muhammed M. Differences in the magnetic properties of $\mathrm{Co}, \mathrm{Fe}$, and $\mathrm{Ni} 250-300 \mathrm{~nm}$ wide nanowires electrodeposited in amorphous anodized alumina templates. Chem. Mater. 2005; 17: 1829-34. http://dx.doi.org/10.1021/cm047870a

[22] Chung CK, Yang CY, Liao MW, Li SL. Fabrication of copper nanowires using overpotential electrodeposition and anodic aluminum oxide template. Micro Nano Lett 2013; 8: 579-81. http://dx.doi.org/10.1049/mnl.2013.0269

[23] Ramazani A, Kashi MA, Montazer AH. Fabrication of single crystalline, uniaxial single domain Co nanowire arrays with high coercivity. J Appl Phys 2014; 115: 113902.

http://dx.doi.org/10.1063/1.4868582

[24] Cattaneoa L, Franza S, Albertini F, et al. Electrodeposition of hexagonal Co nanowires with large magnetocrystalline anisotropy. Electrochimica Acta 2012; 85: 57-65 http://dx.doi.org/10.1016/i.electacta.2012.08.065

[25] Han X, Liu Q, Wang J, Li S, Ren Y, Liu R, Li F. Influence of crystal orientation on magnetic properties of hcp Co nanowire arrays. J Phys D 2009; 42: 095005

http://dx.doi.org/10.1088/0022-3727/42/9/095005

[26] Bachmann J, Escrig J, Pitzschel K, et al. Size effects in ordered arrays of magnetic nanotubes: Pick your reversal mode. J Appl Phys 2009; 105: 07B521.

[27] Cantu-Valle J, Barriga-Castro ED, Vega V, et al. Quantitative magnetometry analysis and structural characterization of multisegmented cobalt-nickel nanowires. J Magnetism Magnetic Mater 2015; 379: 294-9.

http://dx.doi.org/10.1016/j.jmmm.2014.12.022 